\title{
IGF binding protein 2 is a cell-autonomous factor supporting survival and migration of acute leukemia cells
}

\author{
Xiaoli Chen ${ }^{1}$, Junke Zheng ${ }^{1}$, Yizhou Zou ${ }^{1,2}$, Chun Song $^{3}$, Xuemei Hu ${ }^{4}$ and Cheng Cheng Zhang ${ }^{1 *}$
}

\begin{abstract}
Background: The role of IGF binding protein 2 (IGFBP2) in cancer development is intriguing. Previously we identified IGFBP2 as an extrinsic factor that supports the activity of hematopoietic stem cells (HSCs).

Methods and results: Here we investigated the role of IGFBP2 in in human leukemia cells and in the retroviral AML1-ETO9a transplantation acute myeloid leukemia (AML) mouse model.

Results: IGFBP2 is highly expressed in certain human AML and acute lymphoblastic leukemia (ALL) cells. Inhibition of expression of endogenous IGFBP2 in human leukemia cells led to elevated apoptosis and decreased migration and, consistently, to decreased activation of AKT and other signaling molecules. We also studied the effects of IGFBP2 knockout in the retroviral AML1-ETO9a transplantation AML mouse model. The deletion of IGFBP2 in donor AML cells significantly decreased leukemia development in transplanted mice. Lack of IGFBP2 resulted in upregulation of PTEN expression and downregulation of AKT activation, in the mouse AML cells. The treatment of IGFBP2 deficient AML cells with a PTEN inhibitor restored the wild-type colony forming ability. The deletion of IGFBP2 also led to decreased AML infiltration into peripheral organs and tissues, suggesting that IGFBP2 is required for the migration of AML cells out of bone marrow.
\end{abstract}

Conclusion: IGFBP2 is a critical cell-autonomous factor that promotes the survival and migration of acute leukemia cells.

\section{Introduction}

Acute myeloid leukemia (AML) is characterized by rapid proliferation of immature myeloid blasts in the bone marrow. It is the most common acute leukemia affecting adults and accounts for about $1.2 \%$ of cancer deaths in the United States each year. Despite treatment, the majority of the patients relapse within 5 years [1]. To effectively treat AML, new molecular targets and therapeutic approaches need to be identified.

Insulin-like growth factor binding protein 2 (IGFBP2) is a member of the IGFBP family; this family contains at least six circulating proteins that bind IGF-1 and IGF-2 with an affinity equal or greater than that of the three IGF receptors. IGFBPs modulate the biological effects of IGFs by controlling IGF distribution, function, and

\footnotetext{
* Correspondence: alec.zhang@utsouthwestern.edu

'Departments of Physiology and Developmental Biology, University of Texas Southwestern Medical Center, 5323 Harry Hines Boulevard, Dallas 75390, TX, USA

Full list of author information is available at the end of the article
}

activity [2,3]. IGFBP2 preferentially binds IGF-2 over IGF-1. IGFBP2 is expressed in the fetus and in a number of adult tissues and biological fluids [4].

The role of IGFBP2 in cell growth and cancer development is intriguing. While IGFBP2 can bind to IGF ligands and displays IGF-dependent growth inhibitory effects on many cell types, it also has intrinsic bioactivities that are independent of IGF-1 and IGF-2. IGFBP2 binds to the cell surface $[5,6]$ and binds to integrin $\alpha 5$ [6-8] and to $\alpha v$ [9] extracellularly and intracellularly. It stimulates telomerase activity [10], activates MMP-2 [11], modulates MAPK activation [10], and supports proliferation, survival, differentiation, and motility of various types of cells by suppression of PTEN and activation of AKT, integrin, integrin-linked kinase (ILK), and NF- $\mathrm{kB}$ pathways [6-8,10,12-23]. Intracellular IGFBP2 promotes angiogenesis by stimulating VEGF transactivation [24]. In addition, oxidative stress leads to the uptake of IGFBP2 into the cell cytosol after 12-24 h [12,25].

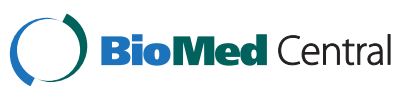


IGFBP2 is expressed at significantly higher levels in AML patients than in healthy volunteers [26]. A lower IGFBP2 level is associated with longer-term survival of patients with AML and ALL $[27,28]$. Expression of IGFBP2 is also an independent factor for the prediction of relapse of AML and ALL [26,27,29,30]. Moreover, IGFBP2 is overexpressed in many patients with other tumors, and in some cases its expression correlates with grade of malignancy $[6,10,12]$. The level of IGFBP2 appears to be low in well-differentiated tumors but high in poorly differentiated tumors [31].

We recently identified IGFBP2 as an extrinsic factor that supports the activity of hematopoietic stem cells (HSCs) $[19,32,33]$. To understand the potential functional role of IGFBP2 in leukemia development, we addressed several questions in the current study: 1) Is IGFBP2 expressed by leukemia cells? If so, what is function for these cells? 2) Is IGFBP2's effect on leukemia cells an environmental effect or cell-autonomous effect? 3) What signaling pathways are regulated by IGFBP2 in leukemia cells? We determined that IGFBP2 supports the survival and migration of acute leukemia cells in a cell-autonomous manner. IGFBP2 is essential for regulation of several signaling pathways including PTEN/AKT signaling in AML and perhaps B-ALL cells.

\section{Results}

IGFBP2 is highly expressed in certain human AML cells

We performed an in silico analysis of IGFBP2 mRNA expression in different subtypes of human AML based on data from the TCGA AML database (http://cancergenome. nih.gov/; accessed November 5, 2012). IGFBP2 is expressed at significantly higher levels in cells of the M3 subtype than of other subtypes tested (Figure 1A). The M3 subtype is characteristic of the acute promyelocytic leukemia (APL) [ $t(15 ; 17)$ ] that generates the fusion protein promyelocytic leukemia-retinoic acid receptor $\alpha$ (PML-RARA).

We further measured IGFBP2 expression in a number of human cancer cell lines including AML and ALL lines. Although IGFBP2 mRNA was expressed at the highest levels in the M3 subtype NB4 AML cells, it was also highly expressed in some other AML and B cell-derived ALL (B-ALL) cells including MV4-11 (M5 AML), U937 (B-ALL), and RCH-ACV (B-ALL) (Figure 1B). By contrast, it was expressed at very low levels in K562 (CML) cells and NALM-6 (B-ALL) cells (Figure 1B).

\section{IGFBP2 is critical for survival and migration of human AML cells}

We studied the potential function of IGFBP2 in human leukemia cells by silencing its expression with lentivirus encoded small hairpin RNAs (shRNAs). Three previously reported RNAi sequences targeting IGFBP2 mRNA [34]

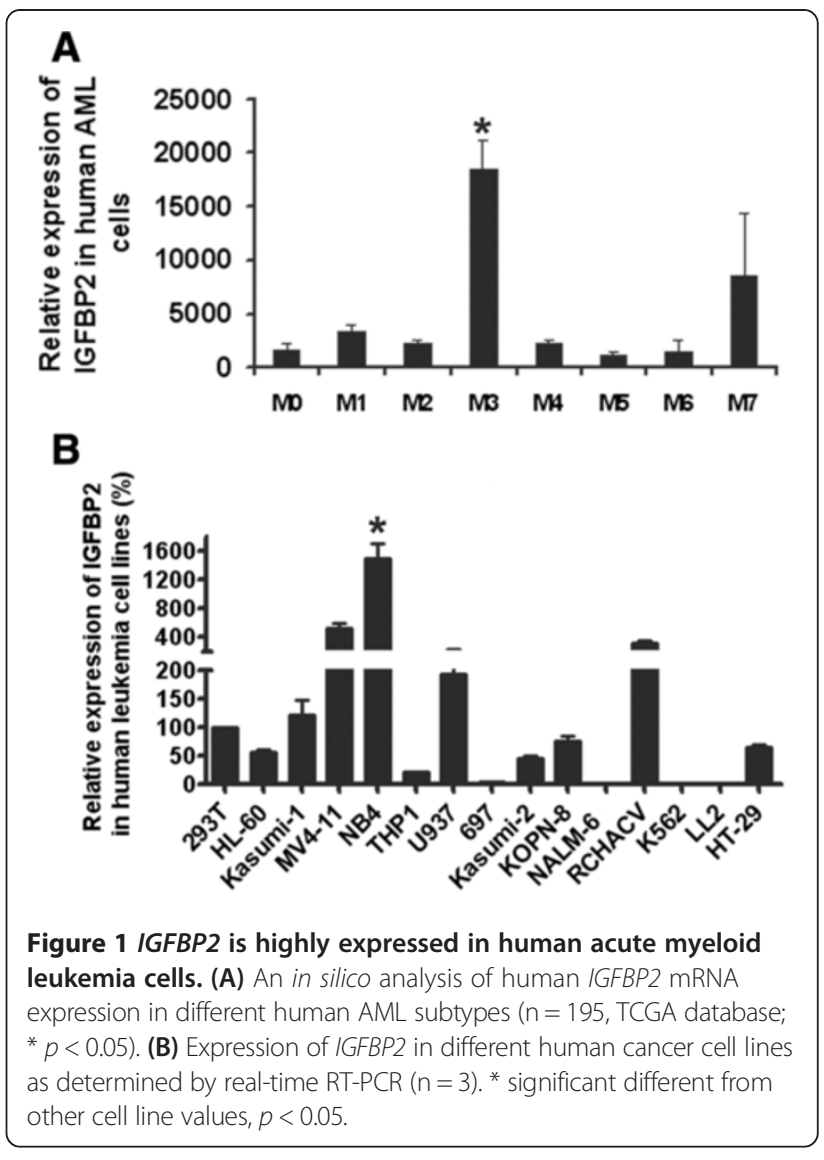

were evaluated; shRNA3 efficiently decreased expression of IGFBP2 mRNA (Figure 2A) and IGFBP2 protein (Figure 2B), concordant with a previous report [35]. Importantly, the inhibition of IGFBP2 expression effectively inhibited the in vitro growth of NB4, MV4-11, U937, and RCHACV cells that express high endogenous IGFBP2 levels (Figure 2C-D) but had little effect on K562 cells or NAML-6 cells that have extremely low levels of IGFBP2 expression (Figure 2E). The inclusion of extrinsic recombinant IGFBP2 in the culture medium did not rescue the defects in leukemia cells treated with shRNA targeting IGFBP2 (Figure 2D). This result suggests that leukemia cells behave differently from HSCs and certain solid cancer cells. While IGFBP2 has cellautonomous effect to support growth of leukemia cells, the extrinsic IGFBP2 stimulates the activity of HSCs and some other cancer cells such as breast cancer cells $[19,23,33]$.

To determine the underlying mechanism by which IGFBP2 supports the growth of leukemia cells, we compared levels of apoptosis and cell cycle status of AML cells treated with shRNA3 or scrambled control shRNA. Cells treated with the shRNA targeting IGFBP2 had increased levels of early and late apoptosis compared to cells treated with the control shRNA (Figure 2F; 0.60\%, 


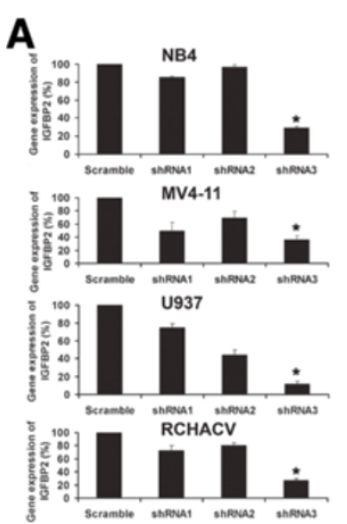

D
B

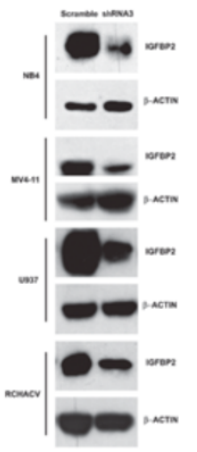

E

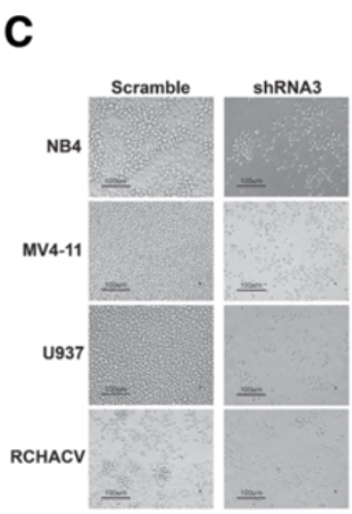

$\mathbf{F}$
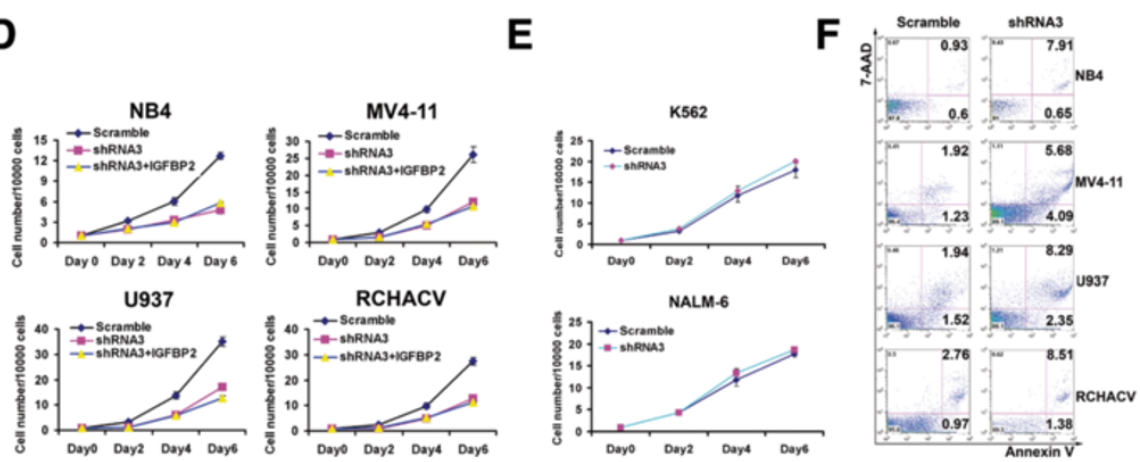

G
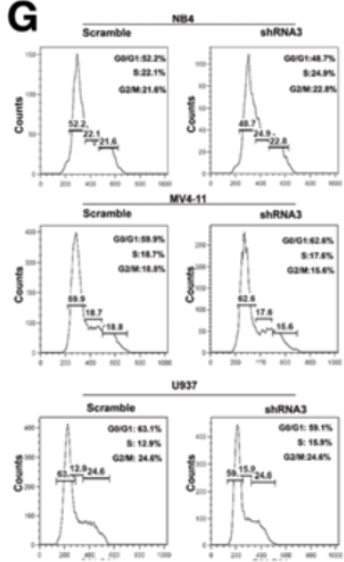

J

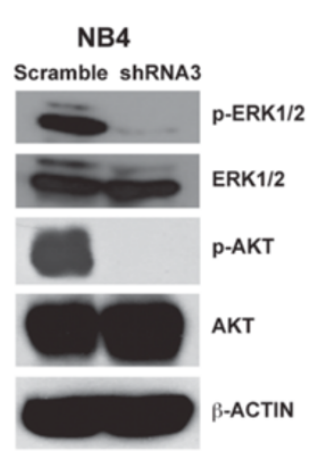

H
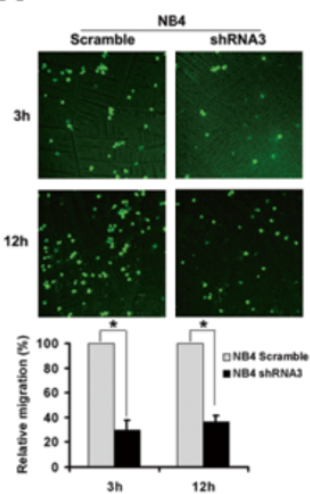

$\mathbf{K}$

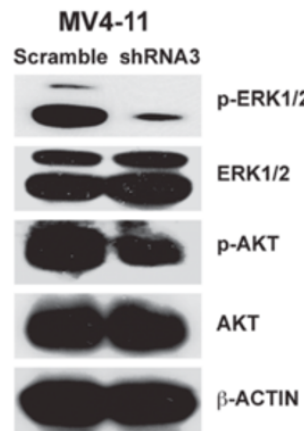

I

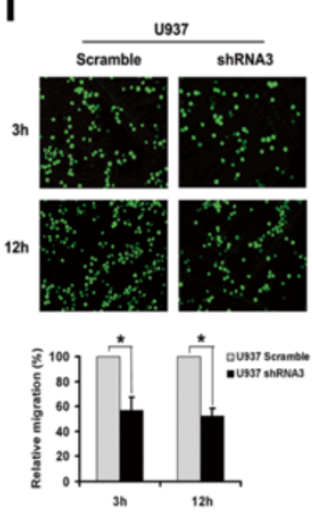

L $\quad$ U937

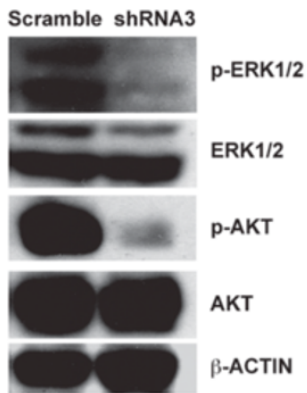

Figure $\mathbf{2}$ (See legend on next page.) 
(See figure on previous page.)

Figure 2 IGFBP2 is critical for survival and migration of human AML cells. (A) IGFBP2 mRNA expression was reduced in four human leukemia cell lines by shRNA3 as determined by real-time RT-PCR $(n=3)$. * significant different from scramble control values, $p<0.05$. (B) IGFBP2 levels were reduced in four human leukemia cell lines by shRNA3 as determined by western blotting $(n=3)$. (C) Inhibition of IGFBP2 expression with shRNA3 in four human leukemia cell lines that have high IGFBP2 levels decreased cell growth in culture $(n=3)$. (D) Effects of inhibition of IGFBP2 expression with shRNA3 cannot be rescued by extrinsic recombinant IGFBP2 protein $(500 \mathrm{ng} / \mathrm{ml})(\mathrm{n}=3)$. (E) Inhibition of /GFBP2 expression with shRNA3 in two human leukemia cell lines that have low IGFBP2 levels did not decrease cell growth in culture $(n=3)$. (F) Inhibition of IGFBP2 expression with shRNA3 in four human leukemia cell lines that have high IGFBP2 levels induced apoptosis as determined by Annexin $v$ and 7-AAD staining in flow cytometry. (G) Inhibition of IGFBP2 expression with shRNA3 did not induce cell cycle arrest in AML cell lines as determined by propidium iodide staining and analysis by flow cytometry. (H-I) Inhibition of IGFBP2 expression with shRNA3 suppressed NB4 and U937 cell migration. Indicated cells transduced with scrambled shRNA or shRNA3 were placed in the upper chamber of a transwell insert (5- $\mu \mathrm{m}$ pore size). Cells were allowed to migrate for 3 or 12 hours at $37^{\circ} \mathrm{C}$ before harvesting and analysis $\left(n=3\right.$; $\left.{ }^{* *} p<0.01\right)$. The migration was normalized by the cell numbers at $12 \mathrm{hr}$. (J-L) Inhibition of /GFBP2 expression with shRNA3 decreased the activation of ERK and AKT in NB4, MV4-11, and U937 cell lines.

$1.23 \%, 1.52 \%$, and $0.97 \%$ early apoptotic cells in controls vs. $0.65 \%, 4.09 \%, 2.35 \%$, and $1.38 \%$ in knockdown cells, and $0.93 \%, 1.92 \%, 1.94 \%$, and $2.76 \%$ late apoptotic cells in controls vs. $7.91 \%, 5.68 \%, 8.29 \%$, and $8.51 \%$ in knockdown cells, at day 6 of culture). In contrast, there was no significant difference in cell cycle distribution between cells treated with control shRNA and shRNA targeting IGFBP2 (Figure 2G). Furthermore, we observed that inhibition of IGFBP2 expression in NB4 or U937 cells decreased cell migration in a transwell assay (Figure 2H-I).

We next examined whether ERK and AKT signaling are involved in the effects of IGFBP2 on these leukemia cells. Compared to control treated cells, NB4, MV4-11, and U937 cells treated with shRNA targeting IGFBP2 had significantly decreased phosphorylation of ERK and AKT (Figure 2J-L). We also observed increased levels of PTEN in NB4 cells (Additional file 1: Figure S1). These results suggest that, as observed in other systems [6-8,10,12-22], ERK and PTEN/AKT signaling pathways are possible effectors of IGFBP2 in human leukemia cells. Together, our results suggest that IGFBP2 has cellautonomous effects on leukemia cells and is critical for their survival and migration.

\section{IGFBP2 supports leukemia development in the mouse AML model}

To gain a deeper understanding of the mechanism by which IGFBP2 supports AML development, we studied AML development in IGFBP2-null mice. While IGFBP2 is expressed at high levels by M3 $\mathrm{t}(15: 17)$ APL cells that produce a fusion protein promyelocytic leukemia-retinoic acid receptor $\alpha$ (PML-RARA), the physiologic PML-RARA expression from the mouse $p m l$ locus rarely causes leukemia development [36]. IGFBP2 is also highly expressed in AML1-ETO cells (Additional file 1: Figure S2) [37], which do cause leukemia development in a transplant model [38]. We, therefore, sought to use IGFBP2-null mice to study how IGFBP2 affects AML development in the AML1-ETO9a (AE9a) retroviral transplantation mouse model [38].
In drastic contrast to the observation that normal HSCs do not show a detectable IGFBP2 mRNA level and differentiated hematopoietic cells express significant amount of IGFBP2 [19], IGFBP2 is highly expressed in both AML stem cells (AML-SC) enriched bone marrow $\mathrm{Lin}^{-} \mathrm{Kit}^{+} \mathrm{Sca}-\mathrm{1}^{-}$cells [38] and differentiated $\mathrm{Lin}^{-} \mathrm{Kit}^{-} \mathrm{Sca}-\mathrm{1}^{-}$ cells in the AML1-ETO9a AML model (Figure 3A). The mice transplanted with the AE9a-transduced IGFBP2null cells developed AML significantly more slowly than controls transplanted with wild-type cells (Figure 3B). All mice transplanted with control AE9a AML cells died within 240 days post-transplantation. In contrast, more than $80 \%$ of mice transplanted with IGFBP2-null counterparts survived longer than 240 days (Figure 3B). The percentages of wild-type $\mathrm{GFP}^{+} \mathrm{AML}$ cells were significantly greater than the null counterparts after 3 months post-transplantation (Figure $3 \mathrm{C}$ ). However, within the $\mathrm{GFP}^{+}$leukemia compartments, there were no significant differences in the AML-SC population or in the more differentiated Mac- $1^{+}, \mathrm{B}_{2} 20^{+}$, or $\mathrm{CD}^{+}$cells in mice that received IGFBP2-null cells and in those transplanted with wild-type cells based on flow cytometry analyses (Figure 3D). Mice transplanted with IGFBP2-null AML cells had significantly decreased liver and spleen sizes than mice transplanted with wild-type cells at 4 months post-transplantation (Figure 3E). The examination of leukemia infiltration into spleen and liver also revealed that IGFBP2-null AML cells less effectively induced leukemia than wild-type AML cells (Figure 3F). The analysis of key signaling molecules revealed that deficiency of IGFBP2 decreased the levels of phosphorylated forms of AKT and STAT3 whereas those of ERK and STAT6 remained unaffected (Figure 3G). Colony forming unit (CFU) assays showed that knockout of IGFBP2 led to a $20 \%$ decrease in CFUs in the primary plating, and more than $30 \%$ of decrease in CFUs in the secondary plating (Figure $3 \mathrm{H}$ ), indicating that IGFBP2 enhances self-renewal of AML cells in vitro. Deficiency of IGFBP2 also altered the morphology of colonies (Figure $3 \mathrm{H}$, upper panels).

We performed secondary transplantation to investigate the role of IGFBP2 in the activity of mouse AML-SCs. 


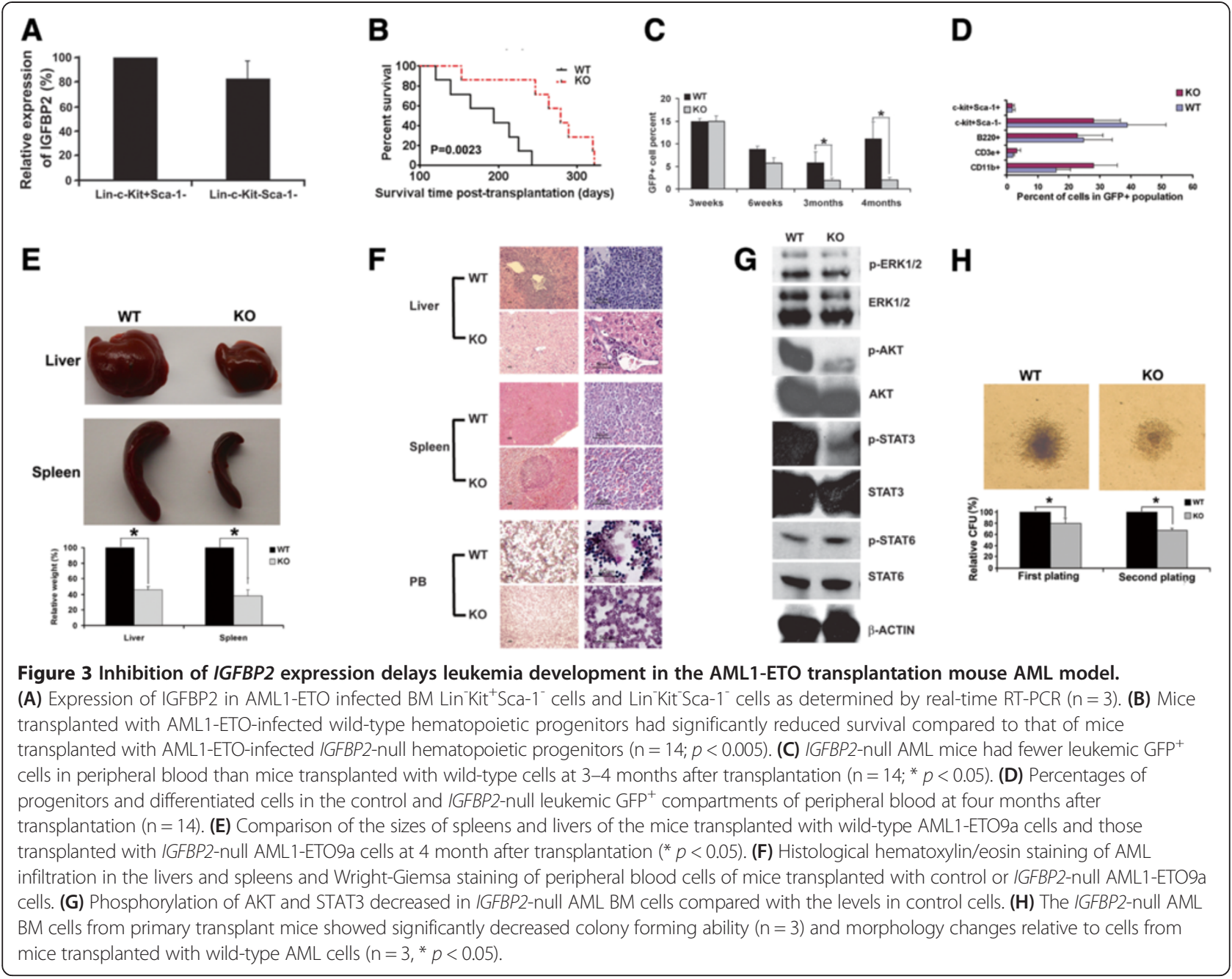

The IGFBP2-null bone marrow AML cells decreased AML development during secondary transplantation (Figure 4A-F) and had dramatically decreased AKT and STAT3 activation (Figure 4G) as was observed in the primary transplanted cells. IGFBP2-null cells resulted in only $5 \%$ of the CFU of wild-type AML cells (Figure $4 \mathrm{H}$ ). Importantly, similar to the human leukemia cells, the deletion of IGFBP2 induced increased apoptosis of mouse bone marrow AML cells (Figure 4I). In both primary and secondary transplantation, PTEN levels were increased in IGFBP2-null AML cells relative to levels in wild-type cells (Figure 4J). Importantly, the PTEN inhibitor bpV(HOpic) was capable of rescuing the CFU defects of null bone marrow AML cells (Figure 4K). Therefore, IGFBP2 supports the survival of AML-SCs, and PTEN/ AKT signaling and STAT3 signaling may play roles in IGFBP2-regulated AML-SC activity.

\section{IGFBP2 supports the mobilization of mouse AML cells}

Because IGFBP2 plays a role in cell migration $[7,11,12,20]$, we compared the distribution of wild-type and IGFBP2- null AML cells in bone marrow and peripheral tissues and organs. Although we found that the percentages of IGFBP2-null AML cells did not differ from those of wild-type cells in BM, the existence of IGFBP2-null AML cells in peripheral blood, spleen, and liver was significantly decreased relative to levels of wild-type AML cells (Figure 5A-B). Concordantly, the expression of surface proteins (CX3CR1, CXCR4, EMB, ITGB4, LSP, VCAM1) important for leukemia infiltration was downregulated in IGFBP2-null bone marrow AML cells (Figure 5C). Together with the migration enhancing effect of IGFBP2 in human leukemia cells (Figure 2H-I), our results suggest that IGFBP2 enhances the mobilization of AML cells, thus accelerating AML development.

\section{Discussion}

Previously, we showed that IGFBP2 stimulates the activities of mouse and human HSCs in vitro and in vivo $[19,32,39]$. Here, we demonstrated that, 1) IGFBP2 is highly expressed by certain types of acute leukemia cells, 2) IGFBP2 is a cell-autonomous factor that promotes 


\section{A}
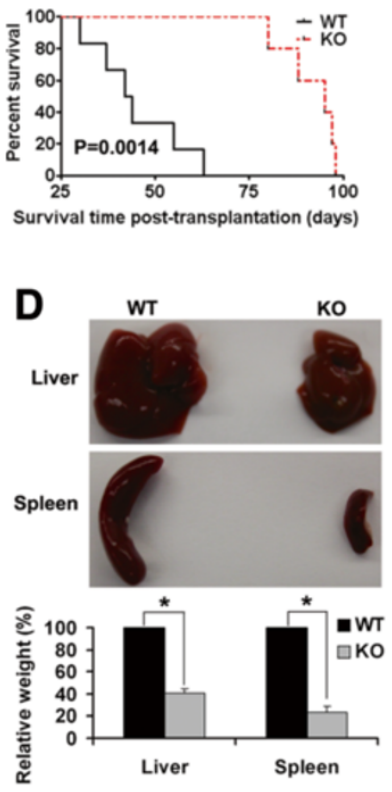

G

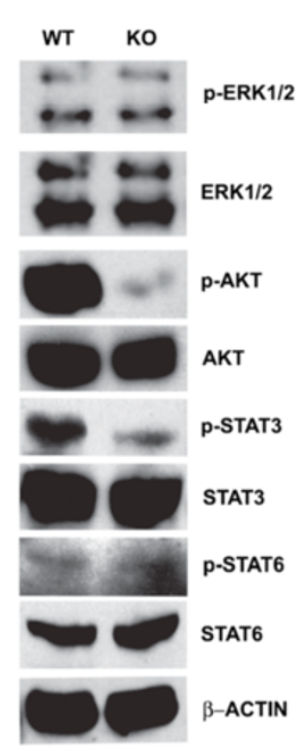

J

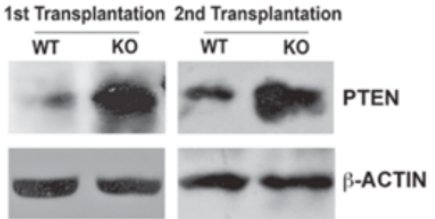

E

H

I
B
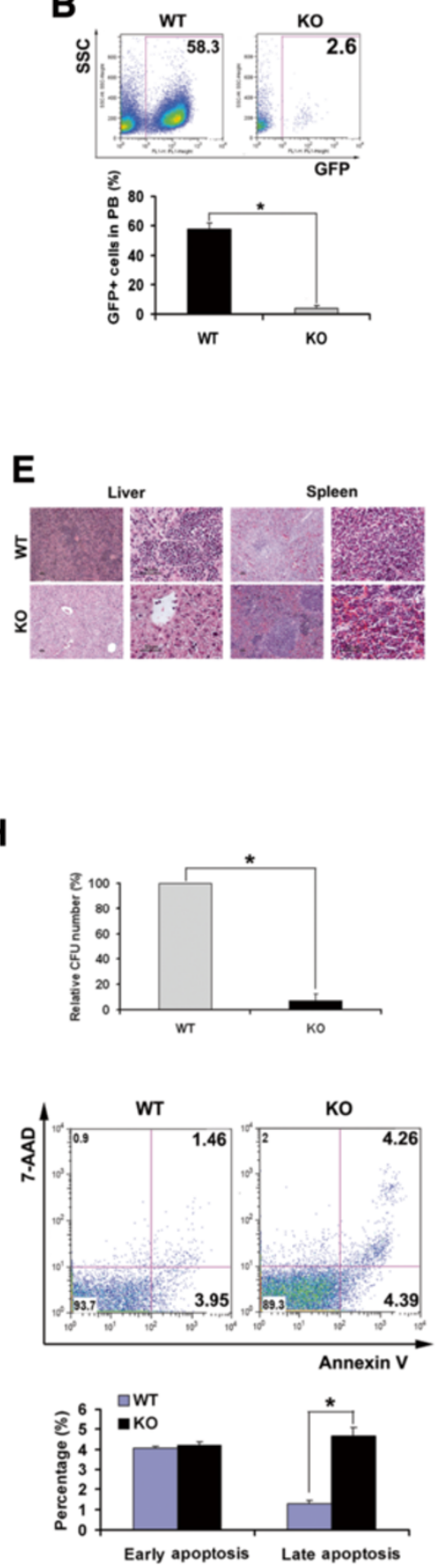

K

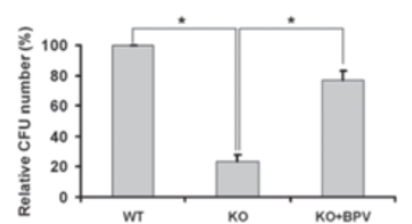

C
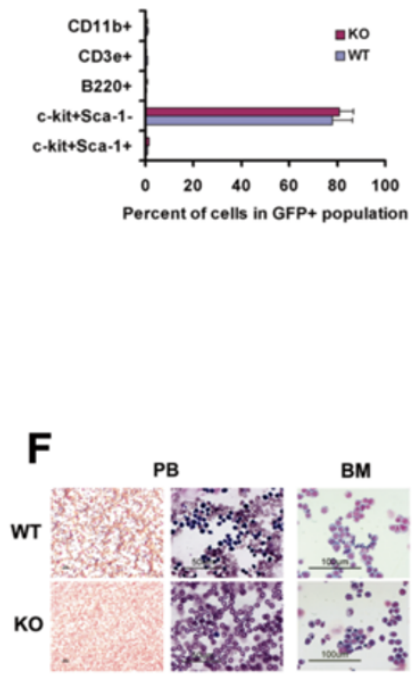

Figure 4 (See legend on next page.) 
(See figure on previous page.)

Figure 4 Knockout of IGFBP2 delays leukemia development in the AML1-ETO AML model upon serial transplantation. (A) Mice transplanted with AML1-ETO-infected wild-type hematopoietic progenitors had significantly reduced survival upon secondary transplantation compared to that of mice transplanted with IGFBP2-null cells $(n=11 ; p<0.01)$. (B) IGFBP2-null AML mice had significantly fewer leukemic GFP ${ }^{+}$ cells in peripheral blood compared to mice transplanted with wild-type cells at 3 weeks after secondary transplantation $\left(n=11\right.$; $\left.{ }^{*} p<0.05\right)$. (C) Percentages of progenitors and differentiated cells in the control and IGFBP2-null leukemic GFP ${ }^{+}$compartments of peripheral blood at 3 weeks after secondary transplantation $(n=10)$. (D) Comparison of the sizes of spleens and livers of the mice transplanted with wild-type and IGFBP2-null AML1-ETO9a cells at 1 month after secondary transplantation (* $p<0.05$ ). (E) Histological hematoxylin/eosin staining of AML infiltration in the livers and spleens of mice secondarily transplanted with control or IGFBP2-null AML1-ETO9a cells. (F) Representative Wright-Giemsa staining of peripheral blood and bone marrow AML cells from leukemic mice after secondary transplantation. (G) Phosphorylation of AKT and STAT3 decreased in IGFBP2null AML BM cells compared with levels in the control cells. (H) IGFBP2-null AML1-ETO9a BM cells from secondarily transplanted mice had dramatically decreased CFU forming ability, including decreased colony number and size, relative to wild-type AML1-ETO9a BM cells $(n=6$; * $p<0.05)$. (I) /GFBP2null AML1-ETO9a BM cells showed increased apoptosis relative to control cells ( $\left.n=6 ;{ }^{*} p<0.05\right)$. (J) AML cells from IGFBP2-null BM showed higher levels of PTEN expression than those from control mice both in primary and secondary transplantation. (K) A PTEN inhibitor increased the CFU activity of IGFBP2-null AML cells $\left(n=3 ;{ }^{*} p<0.05\right)$.

the development of acute leukemia, 3) IGFBP2 supports both survival and migration of leukemia cells, and 4) the stimulating effect of IGFBP2 on acute leukemia cells depends on PTEN signaling. To our knowledge, this is the first functional demonstration that IGFBP2 is critical for leukemia development. Our results are concordant with reports that IGFBP2 is considered a prognostic factor for AML and ALL [26,27,29,30] and activates AKT [7] and suppresses PTEN expression [22,23] in certain solid cancer cells.

It is rather surprising that IGFBP2, a non-essential factor for normal development, is detrimental for acute leukemia cells upon deletion. Our study suggests that the different effects of IGFBP2 on normal HSCs and leukemia cells contribute to this phenomenon. Normal HSCs express little IGFBP2 per se [19], whereas both leukemia stem cells and differentiated leukemia cells have similar high expression of IGFBP2. Consistently, the extrinsic IGFBP2 has a supporting effect on HSC expansion [19,33], and intrinsic IGFBP2 promotes the survival and migration of AML cells (including both AML-SCs and differentiated AML cells) in a cellautonomous manner. Inhibition of IGFBP2 expression in human leukemia cell lines effectively inhibited growth of these cells. Importantly, the exogenous recombinant IGFBP2 added to the culture medium did not have a potent rescue effect. In addition, HSCs and acute leukemia cells represent different cell identities and likely have
A

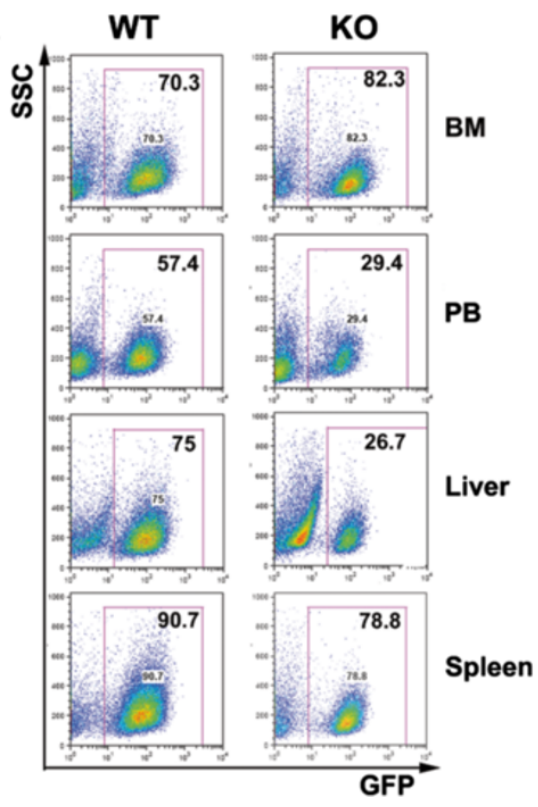

B

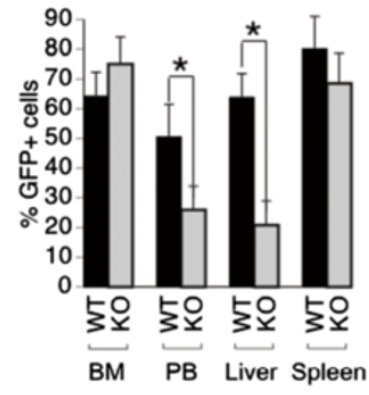

C

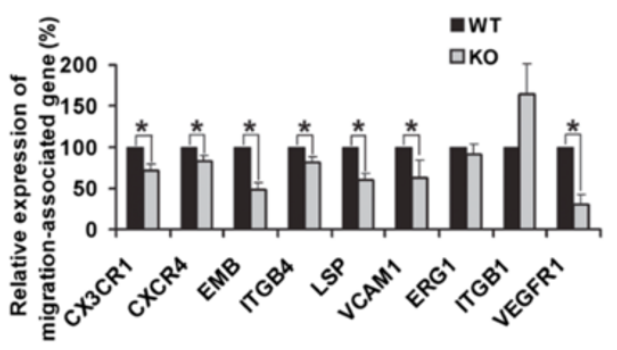

Figure 5 Knockout of IGFBP2 decreases migration of leukemia cells out of bone marrow in the AML1-ETO mouse AML model.

(A-B) Representative flow cytometry plots (A) and summary of results (B) showing the mice transplanted with IGFBP2-null AML cells have significantly decreased GFP+ AML cells in peripheral blood, liver, and spleen but not in BM compared with the mice transplanted with control AML cells. (C) The IGFBP2-null AML BM cells have decreased expression of a number of surface proteins compared to wild-type cells $\left(n=3\right.$; $\left.^{*} p<0.05\right)$. 
very different signaling networks and thus use distinctive mechanisms to utilize IGFBP2. While a major question in IGFBP biology is whether the effect of IGFBP2 is environmental or cell-autonomous, our studies on HSCs and leukemia indicated that the answers are cell-typedependent.

The cell-autonomous effect of IGFBP2 in leukemia cells is also different from the extrinsic effect of IGFBP2 in supporting survival of certain solid cancer cells such as breast cancer cells [23]. Nevertheless, it has been shown that intrinsic IGFBP2 interacts with integrin $\alpha 5 \beta 1$ and promotes migration of glioma cells and glioma progression through activation of AKT, ILK, and NF-kB pathways $[7,8,20]$. Moreover, endogenous IGFBP2 stimulates the transactivation of VEGF and supports angiogenesis [24]. Concordantly, here our study suggested that the AKT pathway in leukemia cells plays a critical role in the effects of IGFBP2, and we demonstrated that the PTEN inhibitor treatment rescues the colony forming activity of the IGFBP2 deficient leukemia cells. Overall, the diverse IGFBP2 actions possibly result from the different cell identities that have distinctive extracellular or intracellular IGFBP2-interacting molecules, and the IGFBP2 related signaling in different cells may be quite different. Indeed, consistent with the different expression of IGFBP2 in HSCs and leukemia cells, the signaling defects we observed in IGFBP2 deficient leukemia cells are more dramatic than in IGFBP2-null HSCs, and also are unique compared to defects observed in other cancer cells upon IGFBP2 deletion [23]. Further investigations are warranted to determine how IGFBP2 has different effects on normal cells and various types of cancer cells.

\section{Conclusion}

Here we showed that IGFBP2 was required for both of survival and migration of AML and ALL cells. The inhibition of IGFBP2 expression in human AML and B-ALL cell lines increased apoptosis and decreased migration, and these results were confirmed in vivo using the IGFBP2-null AML1-ETO9a model. These novel data indicated that IGFBP2 supports leukemia development autonomously by both enhancing cell survival and promoting migration out of bone marrow and infiltration into peripheral organs and tissues. The ability of IGFBP2 to support cancer cell survival or migration has been documented in other cancer cell types. For example, IGFBP2 has anti-apoptotic effects in multiple types of solid cancer $[7,12,13,23]$, binds to integrin $\alpha 5$ resulting in migration of Ewing's sarcoma cells [6], and activates integrin $\beta 1$ to induce glioma cell motility [20]. Because IGFBP2 is not expressed by normal HSCs but highly expressed by leukemia stem cells and differentiated leukemia cells, it is desirable to develop anti-IGFBP2 therapy that may effectively induce apoptosis and block mobilization of leukemia cells including leukemia stem cells with minimal toxicity to normal HSCs.

\section{Methods}

Mice, shRNAs, and primers

C57BL/6 CD45.2 and CD45.1 mice were purchased from the National Cancer Institute and the University of Texas Southwestern Medical Center animal breeding core facility. The IGFBP2 ${ }^{+-}$mice in C57BL/6 background were previously described [19]. Mice were maintained at the University of Texas Southwestern Medical Center animal facility. All animal experiments were performed with the approval of UT Southwestern Committee on Animal Care. Western blots were performed to detect the IGFBP2 protein using a goat anti-IGFBP2 antibody (SC6002; Santa Cruz Biotechnology). The sequences for the shRNAs and RT-PCR primers for human IGFBP2 are listed below.

Scramble shRNA: 5'-GATATGTGCGTACCTAGCAT-3' IGFBP2 shRNA1: 5' -AATGGCGATGACCACTCAGAA-3' IGFBP2 shRNA2: 5' -GATATGTGCGTACCTAGCAT-3' IGFBP2 shRNA3: 5'-ACTGTGACAAGCATGGCCTGT-3' Human IGFBP2 Forward Primer: 5'-GCCCTCTGGA GCACCTCTACT-3'

Human IGFBP2 Reverse Primer: 5'-CATCTTGCAC TGTTTGAGGTTGTAC-3'

\section{Retroviral infection and transplantation}

Human embryonic kidney $293 \mathrm{~T}$ cells were grown in DMEM with $10 \%$ fetal bovine serum (FBS) and transfected with an MSCV-AML1-ETO9a-IRES-GFP encoding plasmid [38] and pCL-ECO to produce retroviruses. The infection of Lin $^{-}$cells with retrovirus was performed as described previously [40]. Briefly, we incubated Lin cells overnight in medium with $10 \% \mathrm{FBS}, 20 \mathrm{ng} / \mathrm{mL}$ SCF, $20 \mathrm{ng} /$ $\mathrm{ml} \mathrm{IL-3,} \mathrm{and} 10 \mathrm{ng} / \mathrm{mL}$ IL-6, followed by spin infection with retroviral supernatant in the presence of $4 \mu \mathrm{g} / \mathrm{mL}$ polybrene. Infected cells $(300,000)$ were transplanted into lethally irradiated (1000 rad) C57BL/6 mice by retro-orbital injection. For secondary transplantation, $\mathrm{GFP}^{+}$ bone marrow $(\mathrm{BM})$ cells from primary transplanted mice were transplanted into mice with 100,000 normal BM cells as competitors.

\section{Flow cytometry, immunohistochemistry, and cytospin}

Flow cytometry, immunohistochemistry, and cytospin were performed as we described previously [40]. For flow cytometry analysis of AML cells, peripheral blood or $\mathrm{BM}$ cells were stained with anti-Lineage-Biotin (followed by streptavidin-APC), anti-Mac-1-APC, antiGr-1-PE, anti-CD3-APC, anti-B220-PE, or anti-Kit-PE monoclonal antibodies (BD Pharmingen). Cell cycle status was determined by propidium iodide staining. For analysis of apoptosis, cells were stained with PE- 
conjugated anti-annexin V and 7-AAD (BD Pharmingen) according to the manufacturer's instructions.

\section{Colony forming unit (CFU) assays}

Cells from AML mice were plated in methylcellulose (M3534, Stem Cell Technologies) for CFU-GM assays, according to the manufacturer's protocols and our previously published protocol [40,41]. After 7 days, 2000 cells from three dishes were used for secondary replating. $1 \mu \mathrm{M}$ PTEN inhibitor bpV(HOpic) (CalBiochem) was used to treat AML cells for the CFU assay as indicated.

\section{Western blotting}

Cell lysates (100 $\mu$ g samples) were separated by electrophoresis on a $4-12 \%$ SDS-polyacrylamide gel, and the proteins were electroblotted onto a nitrocellulose membrane. The membrane was probed with primary antibody for $1 \mathrm{~h}$ at room temperature and then incubated with horseradish peroxidase-conjugated secondary antibody, which was detected with the chemiluminescence SuperSignal kit (Pierce).

\section{Quantitative RT-PCR}

Total RNA was isolated from FACS-collected cells. Firststrand cDNA was synthesized using SuperScript II RT (Invitrogen). Samples were analyzed in triplicate $25-\mu \mathrm{l}$ reactions (300 $\mathrm{nM}$ each primer, $12.5 \mu \mathrm{l}$ of Master mix) as adapted from the standard protocol provided in SYBR Green PCR Master Mix and RT-PCR Protocols provided by Applied Biosystems. Primers were purchased from Qiagen or Sigma. The default PCR protocol was used on an Applied Biosystems Prism 7000 Sequence Detection System. The mRNA level in each population was normalized to the level of $\beta$-actin RNA transcripts present in the same sample as described previously [39].

\section{Statistical analyses}

Data are expressed as mean \pm SEM. Data were analyzed by Student's $t$ test and were considered statistically significant if $p<0.05$. The survival rates of the two groups were analyzed using a log-rank test.

\section{Additional file}

Additional file 1: Figure S1. PTEN levels were increased in NB4 cells treated with shRNA targeting IGFBP2. Figure S2. An in silico analysis of IGFBP2 expression in AML1-ETO transduced CD34+ human cord blood or peripheral blood cells based on the published database in reference 37.

\section{Abbreviations}

ALL: Acute lymphoblastic leukemia; AML: Acute myeloid leukemia; HSCs: Hematopoietic stem cells; IGF: Insulin-like growth factor; IGFBP2: IGF binding protein 2; ILK: Integrin-linked kinase; PTEN: Phosphatase and tensin homolog; WT: Wild-type.

\section{Competing interest}

The authors declare no competing financial interests.

\section{Authors' contributions}

$X C$, JZ, and CCZ contributed to design, performed experiments, interpreted data, and contributed to writing of the manuscript. $Y Z, C S$, and $\mathrm{XH}$ contributed to experimental performance and interpretation. All authors read and approved the final manuscript.

\section{Authors' information}

C.C.Z. is an associate professor at UT Southwestern Medical Center, focusing on the roles of secreted proteins and cell surface receptors in the ex vivo expansion of hematopoietic stem cells and leukemia development.

\section{Acknowledgments}

Support to C. C. Z. is from NIH grant 1R01CA172268, the Leukemia and Lymphoma Society Scholar Award 260071, DOD PR093256, and CPRIT RP100402.

\section{Author details}

${ }^{1}$ Departments of Physiology and Developmental Biology, University of Texas Southwestern Medical Center, 5323 Harry Hines Boulevard, Dallas 75390, TX, USA. ${ }^{2}$ Department of Immunology, Central South University School of Xiangya Medicine, Changsha, China. ${ }^{3}$ Shandong University and National New Drug R\&D Center in Shandong, Jinan, China. ${ }^{4}$ Department of Immunology, Binzhou Medical University, Yantai, China.

Received: 29 August 2013 Accepted: 20 September 2013 Published: 8 October 2013

\section{References}

1. Appelbaum FR, Rowe JM, Radich J, Dick JE: Acute myeloid leukemia. Hematology Am Soc Hematol Educ Program 2001:62-86.

2. Ranke MB, Elmlinger M: Functional role of insulin-like growth factor binding proteins. Horm Res 1997, 48(Suppl 4):9-15.

3. Kibbey MM, Jameson MJ, Eaton EM, Rosenzweig SA: Insulin-like growth factor binding protein-2: contributions of the C-terminal domain to insulin-like growth factor-1 binding. Mol Pharmacol 2006, 69:833-845.

4. Rajaram S, Baylink DJ, Mohan S: Insulin-like growth factor-binding proteins in serum and other biological fluids: regulation and functions. Endocr Rev 1997, 18:801-831.

5. Russo VC, Bach LA, Werther GA: Cell membrane association of insulin-like growth factor binding protein-2 (IGFBP-2) in the rat brain olfactory bulb. Prog Growth Factor Res 1995, 6:329-336.

6. Schutt BS, Langkamp M, Rauschnabel U, Ranke MB, Elmlinger MW: Integrinmediated action of insulin-like growth factor binding protein-2 in tumor cells. J Mol Endocrinol 2004, 32:859-868.

7. Dunlap SM, Celestino J, Wang H, Jiang R, Holland EC, Fuller GN, Zhang W: Insulin-like growth factor binding protein 2 promotes glioma development and progression. Proc Natl Acad Sci U S A 2007, 104:11736-11741.

8. Wang GK, Hu L, Fuller GN, Zhang W: An interaction between insulin-like growth factor-binding protein 2 (IGFBP2) and integrin alpha5 is essential for IGFBP2-induced cell mobility. J Biol Chem 2006, 281:14085-14091.

9. Pereira JJ, Meyer T, Docherty SE, Reid HH, Marshall J, Thompson EW, Rossjohn J, Price JT: Bimolecular interaction of insulin-like growth factor (IGF) binding protein-2 with alphavbeta3 negatively modulates IGF-Imediated migration and tumor growth. Cancer Res 2004, 64:977-984.

10. Moore MG, Wetterau LA, Francis MJ, Peehl DM, Cohen P: Novel stimulatory role for insulin-like growth factor binding protein-2 in prostate cancer cells. Int J Cancer 2003, 105:14-19.

11. Wang $H$, Shen W, Huang H, Hu L, Ramdas L, Zhou YH, Liao WS, Fuller GN, Zhang W: Insulin-like growth factor binding protein 2 enhances glioblastoma invasion by activating invasion-enhancing genes. Cancer Res 2003, 63:4315-4321.

12. Hoeflich A, Reisinger R, Lahm H, Kiess W, Blum WF, Kolb HJ, Weber MM, Wolf E: Insulin-like growth factor-binding protein 2 in tumorigenesis: protector or promoter? Cancer Res 2001, 61:8601-8610.

13. Migita T, Narita T, Asaka R, Miyagi E, Nagano H, Nomura K, Matsuura M, Satoh Y, Okumura S, Nakagawa K, et al: Role of insulin-like growth factor 
binding protein 2 in lung adenocarcinoma: IGF-independent antiapoptotic effect via caspase-3. Am J Pathol 2010, 176:1756-1766.

14. Kim DS, Cho HJ, Yang SK, Shin JW, Huh CH, Park KC: Insulin-like growth factor-binding protein contributes to the proliferation of less proliferative cells in forming skin equivalents. Tissue Eng Part A 2009, 15:1075-1080

15. Hsieh D, Hsieh A, Stea B, Ellsworth R: IGFBP2 promotes glioma tumor stem cell expansion and survival. Biochem Biophys Res Commun 2010, 397:367-372.

16. Chakrabarty $S$, Kondratick L: Insulin-like growth factor binding protein-2 stimulates proliferation and activates multiple cascades of the mitogenactivated protein kinase pathways in NIH-OVCAR3 human epithelial ovarian cancer cells. Cancer Biol Ther 2006, 5:189-197.

17. Bartling B, Koch A, Simm A, Scheubel R, Silber RE, Santos AN: Insulin-like growth factor binding proteins- 2 and -4 enhance the migration of human CD34-/CD133+ hematopoietic stem and progenitor cells. Int J Mol Med 2010, 25:89-96.

18. Russo VC, Schutt BS, Andaloro E, Ymer SI, Hoeflich A, Ranke MB, Bach LA Werther GA: Insulin-like growth factor binding protein-2 binding to extracellular matrix plays a critical role in neuroblastoma cell proliferation, migration, and invasion. Endocrinology 2005, 146:4445-4455.

19. Huynh H, Zheng J, Umikawa M, Zhang C, Silvany R, lizuka S, Holzenberger $M$, Zhang W, Zhang CC: IGF binding protein 2 supports the survival and cycling of hematopoietic stem cells. Blood 2011, 118:3236-3243.

20. Holmes KM, Annala M, Chua CY, Dunlap SM, Liu Y, Hugen N, Moore LM, Cogdell $D$, Hu L, Nykter $M$, et al: Insulin-like growth factor-binding protein 2-driven glioma progression is prevented by blocking a clinically significant integrin, integrin-linked kinase, and NF-kappaB network. Proc Natl Acad Sci U S A 2012, 109:3475-3480.

21. Mehrian-Shai R, Chen CD, Shi T, Horvath S, Nelson SF, Reichardt JK, Sawyers $\mathrm{CL}$ : Insulin growth factor-binding protein 2 is a candidate biomarker for PTEN status and PI3K/Akt pathway activation in glioblastoma and prostate cancer. Proc Natl Acad Sci U S A 2007, 104:5563-5568.

22. Perks CM, Vernon EG, Rosendahl AH, Tonge D, Holly JM: IGF-II and IGFBP-2 differentially regulate PTEN in human breast cancer cells. Oncogene 2007, 26:5966-5972.

23. Foulstone EJ, Zeng L, Perks CM, Holly JM: Insulin-like growth factor binding protein 2 (IGFBP-2) promotes growth and survival of breast epithelial cells: novel regulation of the estrogen receptor. Endocrinology 2013, 154:1780-1793.

24. Azar WJ, Azar SH, Higgins S, Hu JF, Hoffman AR, Newgreen DF, Werther GA, Russo VC: IGFBP-2 enhances VEGF gene promoter activity and consequent promotion of angiogenesis by neuroblastoma cells. Endocrinology 2011, 152:3332-3342.

25. Besnard V, Corroyer S, Trugnan G, Chadelat K, Nabeyrat E, Cazals V, Clement A: Distinct patterns of insulin-like growth factor binding protein (IGFBP)2 and IGFBP-3 expression in oxidant exposed lung epithelial cells. Biochim Biophys Acta 2001, 1538:47-58.

26. Dawczynski K, Kauf E, Zintl F: Changes of serum growth factors (IGF-I,-II and IGFBP-2,-3) prior to and after stem cell transplantation in children with acute leukemia. Bone Marrow Transplant 2003, 32:411-415.

27. Vorwerk P, Mohnike K, Wex H, Rohl FW, Zimmermann M, Blum WF, Mittler $U$ : Insulin-like growth factor binding protein-2 at diagnosis of childhood acute lymphoblastic leukemia and the prediction of relapse risk. J Clin Endocrinol Metab 2005, 90:3022-3027.

28. Hattori H, Matsuzaki A, Suminoe A, Koga Y, Tashiro K, Hara T: Identification of novel genes with prognostic value in childhood leukemia using CDNA microarray and quantitative RT-PCR. Pediatr Hematol Oncol 2006, 23:115-127.

29. Dawczynski K, Kauf E, Schlenvoigt D, Gruhn B, Fuchs D, Zintl F: Elevated serum insulin-like growth factor binding protein-2 is associated with a high relapse risk after hematopoietic stem cell transplantation in childhood AML. Bone Marrow Transplant 2006, 37:589-594.

30. Dawczynski K, Steinbach D, Wittig S, Pfaffendorf N, Kauf E, Zintl F: Expression of components of the IGF axis in childhood acute myelogenous leukemia. Pediatr Blood Cancer 2008, 50:24-28.

31. Akmal SN, Yun K, MacLay J, Higami Y, Ikeda T: Insulin-like growth factor 2 and insulin-like growth factor binding protein 2 expression in hepatoblastoma. Hum Pathol 1995, 26:846-851.

32. Zhang CC, Kaba M, lizuka S, Huynh H, Lodish HF: Angiopoietin-like 5 and IGFBP2 stimulate ex vivo expansion of human cord blood hematopoietic stem cells as assayed by NOD/SCID transplantation. Blood 2008, 111:3415-3423.

33. Huynh H, Llizuka S, Kaba M, Kirak O, Zheng J, Lodish HF, Zhang CC: GFBP2 secreted by a tumorigenic cell line supports ex vivo expansion of mouse hematopoietic stem cells. Stem Cells 2008, 26:1628-1635

34. Ben-Shmuel A, Shvab A, Gavert N, Brabletz T, Ben-Ze'ev A: Global analysis of L1-transcriptomes identified IGFBP-2 as a target of ezrin and NF-kappaB signaling that promotes colon cancer progression. Oncogene 2013, 32:3220-3230.

35. Fukushima T, Tezuka T, Shimomura T, Nakano S, Kataoka H: Silencing of insulin-like growth factor-binding protein-2 in human glioblastoma cells reduces both invasiveness and expression of progression-associated gene CD24. J Biol Chem 2007, 282:18634-18644.

36. Welch JS, Yuan W, Ley TJ: PML-RARA can increase hematopoietic selfrenewal without causing a myeloproliferative disease in mice. J Clin Invest 2011, 121:1636-1645.

37. Mulloy JC, Jankovic V, Wunderlich M, Delwel R, Cammenga J, Krejci O, Zhao H, Valk PJ, Lowenberg B, Nimer SD: AML1-ETO fusion protein up-regulates TRKA mRNA expression in human CD34+ cells, allowing nerve growth factor-induced expansion. Proc Natl Acad Sci U S A 2005, 102:4016-4021.

38. Yan M, Kanbe E, Peterson LF, Boyapati A, Miao Y, Wang Y, Chen IM, Chen Z, Rowley JD, Willman $C L$, Zhang DE: A previously unidentified alternatively spliced isoform of $t(8 ; 21)$ transcript promotes leukemogenesis. Nat Med 2006, 12:945-949.

39. Huynh H, lizuka S, Kaba M, Kirak O, Zheng J, Lodish HF, Zhang CC: Insulinlike growth factor-binding protein 2 secreted by a tumorigenic cell line supports ex vivo expansion of mouse hematopoietic stem cells. Stem Cells 2008, 26:1628-1635.

40. Zheng J, Umikawa M, Cui C, Li J, Chen X, Zhang CC, Huynh H, Kang X, Silvany $R$, Wan $X$, et al: Inhibitory receptors bind Angptls and support blood stem cells and leukemia development. Nature 2012, 485:656-660.

41. Zheng J, Umikawa M, Zhang S, Huynh H, Silvany R, Chen BP, Chen L, Zhang CC: Ex vivo expanded hematopoietic stem cells overcome the MHC barrier in allogeneic transplantation. Cell Stem Cell 2011, 9:119-130.

doi:10.1186/1756-8722-6-72

Cite this article as: Chen et al:: IGF binding protein 2 is a cell-

autonomous factor supporting survival and migration of acute leukemia cells. Journal of Hematology \& Oncology 2013 6:72.

\section{Submit your next manuscript to BioMed Central and take full advantage of:}

- Convenient online submission

- Thorough peer review

- No space constraints or color figure charges

- Immediate publication on acceptance

- Inclusion in PubMed, CAS, Scopus and Google Scholar

- Research which is freely available for redistribution 